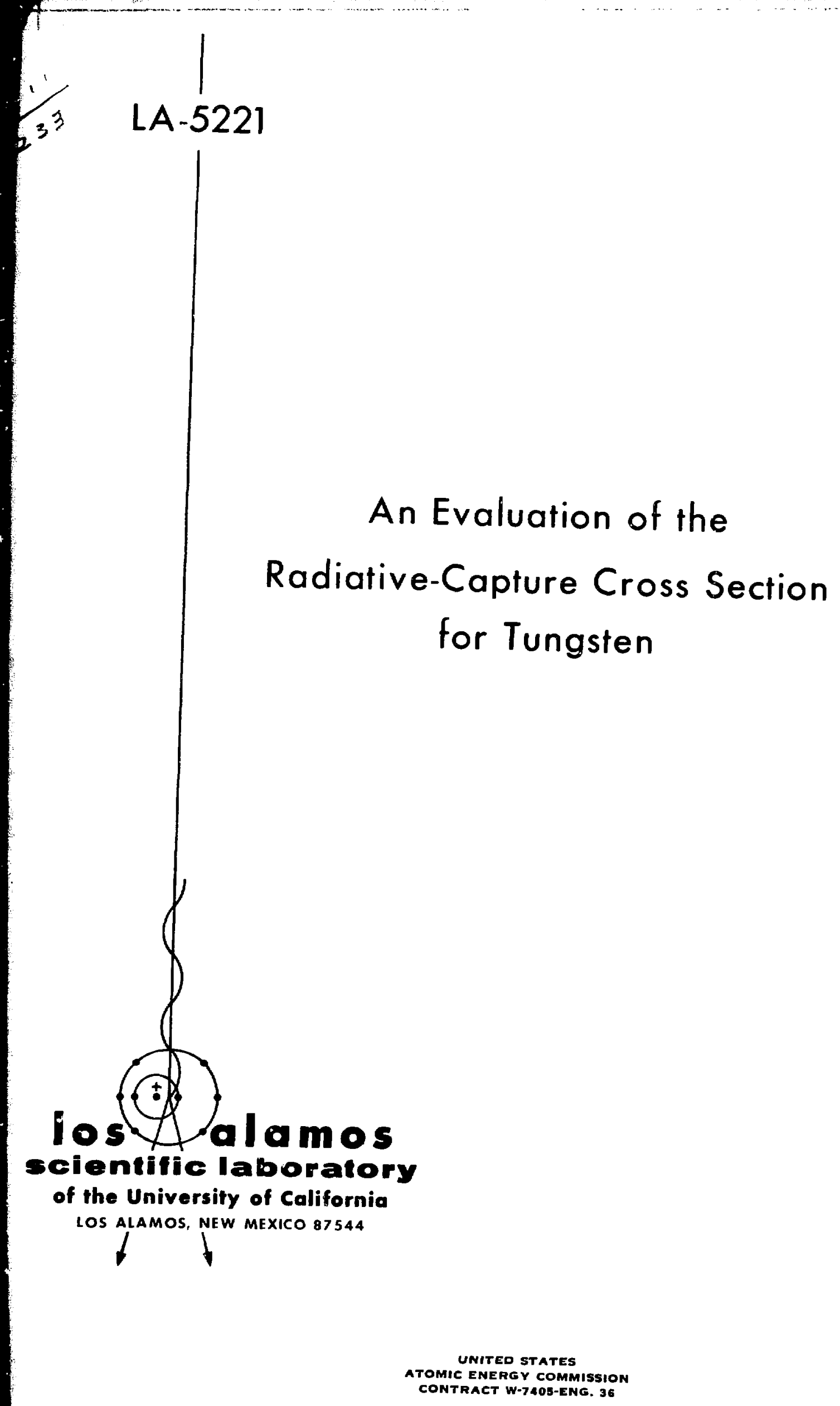

An Evaluation of the

Radiative-Capture Cross Section for Tungsten 
This report was prepared as an account of work sponsored by the United States Government. Neither the United States nor the United States Atomic Energy Commission, nor any of their employees. nor any of their contrac. tors, subcontractors, or their employees, makes any warranty, express or im plied, or assumes any legai liability or responsibility for the accuracy. com pleteness or usefulness of any information, apparatus, product or process dis closed. or represents that its use would not infringe privately owned rights.

Printed in the United States at America. Avaiłabte from National Technical Intormation Service

U. G. Department of Commerce 5285 Port Royal Road

Springlield. Virginia 22151

Price: Printed Copy Sown: Microliche $\mathbf{5 0 . 9 5}$

s.o 
LA.5221

UC.34

ISSUED: May 1973

\title{
An Evaluation of the Radiative-Capture Cross Section for Tungsten
}

by

\author{
J. J. Devaney
}

\begin{abstract}
This reporl was prepared as an account of work sponcored by the United States Govesnment. Neither the United States nor ths United States Atomic Energy Commission, nor any of their employees, nor any of thel contractors, subcontractors, or their employees. makes any warbinty, express of implied, or susumes any legal liability or responsibility fot the accuracy, com. plelenes or usefutness of any information, apparatus, pruduct or process disclosed, or represents ihat its use would nut inftinge privately owned rights.
\end{abstract}


AN EVALUATION OF THE RADIATTVE-CAPTURE CROSS SECTION FOR TUNGSTEN

by

J. J. Devaney

ABSTRACT

An evaluation of the smooth neutron radiative-capture cross section for turgsten and its isotopes between 0.006 and $20 \mathrm{MeV}$ is presented. Included are multiple-reaction corrections to the data which lower the cross section appreciably, especially above $1 \mathrm{MeV}$. The results are available in ENDF/B format.

\section{IMTRODUCTION}

This paper, an interim report on the evaluaticn of tungsten neutron cross sections, gives the smooth radiative-capture cross sections from about 0.006 to $20 \mathrm{MeV}$. We have continued the conservative philosophy of the first paper in this series (De72a); that is, the expected fluctuations at low energy have not been displayed because they could not be substantiated from author to author nor from 1sotope to isotope. This remark is perhaps borderline for normal tungsten between 0.04 and $0.1 \mathrm{MeV}$ (see Fig. 1 at the end of the report) where several authors (Gi6l, Fr70, Ba69) partially agree on some fluctuation; however, this agreement is nct substantiated by comparison of the abundance-weighted isotopic sum with nutural tungsten, and it 16 even contradicted by others (e.B. Po67). We do find significant differences between the 1sotopjc crosssections, supported both by data and theory, with a reversal in relative magnitude of the lootopes at about $0.2 \mathrm{MeV}$. This reversal is caused by the differing onset and importance of inelastic-scattering competition. Beyond $3.4 \mathrm{keV}$, we cannot justify any isotopic differences, so only the natural ele. ment is offered (See Fig. 16). The cross section above about $7 \mathrm{MeV}$ is expected to result largely from direct and collective (semidirect) processes (C165, Br64, Gu66, Lo68, Be68, Be71, Lo70, Ve67, Be70, La59, Lo69, but see also Da64 and Sp69 who would permit higher statistical contributions). In our evaluation, we have welghted experiment according to the stated error, point scatter, comparisone with other data, age, consistency, extensiveness, and general theoretical expectations. Wherever we could determine the sample size, we mede multiple reaction corrections (Dr71, De72b, De73). However, without known sanple sizes and the consequent amount of the multiple reaction correction needed, we are forced to regard some of the data above 1 MeV as only upper bounds to the true cross sections. These data are so indicated in the figures by downward directed arrows.

\section{RESUITS}

We present the amooth capture cross sections in a serles of graphs, (Figs. 1-16), together with exferimental points as corrected for multiple reactions (De73) and for revised atandard cross sectiona where appropriate. We have put error bare on only a few representative pointa for clarity. References to experiment are given on each graph. Above $3.4 \mathrm{keV}$, the curve for $186_{W}(51 \mathrm{~g} .16)$ is our best estimate for 211 1sos.opes. Above $1 \mathrm{MeV}, \mathrm{all}$ even isotopes are given by $186 \mathrm{~W}, \mathrm{Fig} .15$. The swooth crose sections are also given in tabular form in Appendix A, (ENDF/B format - Dr70).

The smooth curve through the date was generated from weighted cross-section averages over variable energy intervals. Intervala and numbers of experimentel pointa were varied widely as appropriate to en optimum deacription of tho amooth curves. Initial analyses were readjusted within orrors so that the abundence-welghted 1sotopic suse matiched the normal element to within experimental error. 
$180_{\mathrm{W}}$ (0.005\%) $0.135 \%$ ( $N$ i 58 ) ] and other isotopes $(0.005 \%)$ were combined with ${ }^{182} w(26.42 \%)$ for an effective abundance of $26.55 \%$, and 183 was taken as $14.40 \%, 184 \mathrm{~W}$ as $30.64 \%$, and $186 \mathrm{~W}$ as $28.41 \%$ (Ni 58). The atomic weight of natural thussten is 183.85 .

\section{DISCUSSION}

A. 0.1- to 3.4-MeV Neutron Energy. Comparison of our curves for $w$ and $186_{W}$, (Fig. 6 vs Fig. 10), shows that $\sigma_{n 7}\left(186_{w}\right)$ crosses from below to abcve $\sigma_{n \gamma}(w)$ at about $0.23 \mathrm{MeV}$. Interpreting this effect to be the more successful competition of inelastic scattering of the lighter isotopes, especially the odd isotope, $183 \mathrm{~W}$, we have constructed the curves of Figs. 7-9 and 11-14. Onset of inelastic scattering is appreciable above the first level of the target, which is $0.1001 \mathrm{MeV}$ for $182_{W}$ ( $(\mathrm{a} 666), 0.0465 \mathrm{MeV}$ for $183_{\mathrm{W}}$ (Ar66), $0.1112 \mathrm{MeV}$ for ${ }^{184} \mathrm{~W}$ (Ma66), and $0.1225 \mathrm{MeV}$ for $186_{W}$ (Gov 66). The $\left(n, m^{\prime}\right)$ reaction, which also contributes below the first excited level of the target, is expected to be negligible within the accuracy of our estimates of the effect of inelastic scattering on the capture cross section, (See Ref. It of De73 for further discussion.) We used identities of the form

$$
\sigma_{n \gamma}=\sigma_{\mathrm{FCN}} \frac{\sigma_{n \gamma}}{\sigma_{\mathrm{cni1}}+\sigma_{n n^{\prime}}+\sigma_{n \gamma}}
$$

to estimate the competition of inelastic scattering. $\sigma_{\mathrm{FCN}} \equiv \sigma_{\mathrm{cnn}}+\sigma_{\mathrm{nn}}+\sigma_{\mathrm{ny}}$ is the compound-nucleusformation cross section; $\sigma_{\mathrm{cnn}}$ is the compound elastic cross section; and $\sigma_{n n}$ ' is the total inelastic scattering. These parameters were taken from experiment, extrapolated from experiment, and estimated from optical-model calculations. The results were then revised to fit $\sigma_{T}$ (De72a), as well as the known experimental $\sigma_{n 7}$ self-consistently for $W$ and $186_{W}$ plus $182_{N}, 183_{W}$, and $184 W$ only up to $0.1 \mathrm{MeV}$. All cross sections were further adjusted within errors so that the ebundanceweighted isotopic sum gave the normal tungsten cross section to well within experimental error. In the above, we used tive inelastic scattering date of Lister et 21 . ( 1257 and Gol66) for ${ }^{182} \mathrm{w}$, $184 \mathrm{~W}$, and $186 \mathrm{~W}$. $183_{\mathrm{W}}$ inelastic scattering was estimated on the basis of the Artna level scheme (Ar65). It might be noted that this procedure gave cross sections differing by about a factor of 2 from the high-energy capture data of Kononov et al. (Ko: 6 ), which date we argue are justifiably rejected because of the equal disagreement of Kononov et al. not only with our above deseribed extrapolation above $0.1 \mathrm{KeV}$, out also with the $186_{\mathrm{W}}$ weighted average curve at $0.1-0.17 \mathrm{MeV}$ ( see Fig. 10). Their data also disagree with the $W$ curve (see Fig. 6 ). Reliable data for $182_{\mathrm{W}}, 183_{\mathrm{W}}$, and $184_{\mathrm{W}}$ end at $0.1 \mathrm{MeV}$. We do carry the eveluations for ${ }^{182} \mathrm{~W}$ and $184_{W}$ distinct from $186_{W}$ to about $1 \mathrm{MeV}$ according to the foregoing prescription in order to eccourt for the natural vs 186 cross-section difference. Beyond $1 \mathrm{MeV}$, we expect a gradual equivalence in cross section for the even isotopes, but, perhaps more importantly, we have elready extrapolated $0.9 \mathrm{MeV}$ above any datum. Consequently, we blend $182_{W}$ and $184 \mathrm{~W}$ into ${ }^{186} \mathrm{~W}$ at about $1 \mathrm{MeV}$. However we keep 18. 183. is predicted to be smaller than for the even isotopes until about $3.4 \mathrm{MeV}$, where lack of cata forces us to one curve for all isotopes. Convergence of the $\sigma_{n \gamma}$ curves is somewhat expected since one believes that isotopic differences tend to disappear at high energy, especially for the dominant collective giant-resonance part.

B. 3.4- to 20-MeV Neutron Energy.

As noted above, we offer one curve for all isotopes in this range (Fig. 16). We have data at 3-4 $\mathrm{KeV}$ for $186 \mathrm{~W}$ and at $14.1 \mathrm{MeV}$ for $\mathrm{A}=181$ and 197 ( Dr71). We know that the compound-nucleus process dominates at $10 \mathrm{cr}$ energy and the direct and giant-resonance collective processes dominate at the midale energies (C165, Br64, Be68, Be70, Be71, L068, Lo69, Lo70, Gu66, Ve67, and La59, but see also Da64 and Sp69). Therefore, for the lower energies in this range, we take as a guide the work of Lene and Lynn (theory-Is59), Schnittroth for ${ }^{197} \mathrm{Au}$ (theory-Sc72), Barry et al. for ${ }^{238_{U}}$ (expt.-Ba64), and Bergqvist et al. for ${ }^{58}$;: (expt. and theoryBe68). From '7-15 MeV we are guided by Coulomb unfolded $(p, \gamma)$ cross sections $\left({ }^{142} \mathrm{Ce}(p, \gamma)^{14} 3_{\mathrm{Pr}}\right.$, DeG4

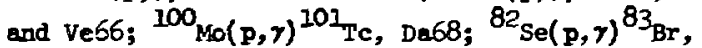
Da68; ${ }^{130} \mathrm{Te}(\mathrm{p}, \gamma)^{131} \mathrm{I}, \mathrm{Da} 64 ;{ }^{209} \mathrm{Bi}(\mathrm{p}, \gamma)^{210} \mathrm{Po}$, Da64 ;

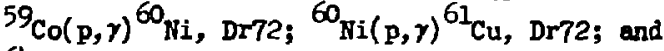
$\left.{ }^{64} \mathrm{Zn}(\mathrm{p}, \gamma) 65 \mathrm{Ga}, \mathrm{Dr} 72\right)$; and by $(n, \gamma)$ cross sections 
on elements other than tungsten $\left({ }^{206} \mathrm{~Pb}(\pi, \gamma){ }^{207} \mathrm{~Pb}\right.$, Be70; ${ }^{58} \mathrm{Ni}(n, \gamma)^{59} \mathrm{Ni}$, Be68; ${ }^{40} \mathrm{Ca}(n, \gamma)^{41} \mathrm{Ca}, \mathrm{Be} 72 \mathrm{a}$;

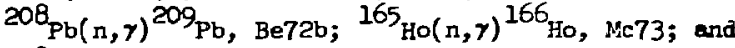
$\left.{ }^{238_{U}(n, r)}{ }^{239} \mathrm{u}, \mathrm{Mc73}\right)$. We unfold the coulom peneiration from the proton reections using the code PENET kindly supplied by P. G. Young (Yo72).

In estimating the trend of $\sigma_{n, \gamma}$ above $15 \mathrm{MeV}$ we have been guided by Gutfreund and Rakavy (Gu66) and by Lungo and Sapcretti (LO68).

\section{ACKNOWLEDGEMERNTS}

It is a pleasure to acknowledge the help of D. M. Drake, P. G. Young, D. R. Harris, and R. J. LaBauve. We are grateful for private commuications of date from D. Drake, D. McDaniels, and P. G. Young; from the National Neutron Cross Section Center, Brookhaven National Laboratory by M. Goldberg; and from the Livermore Experimental Cross Section Information Library (refer to the University of California report series, UCRI-50400), Lawrence Livermore Laboratory, by R. J. Howerton. We are also pleased to ecknowledge drafting and clerical help from B. Powell, D. MeClellan, and N. Whittemore, as well as a critical reading by D. G. Foster, Jr.

\section{REFERENCES}

Ar66. A. Artna, Nuc1. Data Bl-1-37 (1966).

Ba64. J. F. Barry, J. Bunce, and P. H. White, J. Nucl. Energy 18, 481 (1964).

Ba69. Z. M. Bartolome, R. W. Hockenbury, W. R. Moyer, J. R. Tatarczuk, and R. C. Block, "Neutron Radiative Capture and Transmission Measurements of $\mathrm{W}$ and $\mathrm{Zr}$ Isotopes in the keV Region," Nucl. Sci. Eng. 37, 137 (1969).

Be58. T. S. Belanova, Soviet Physice-JETP 7, 397 (1958); and At. Energ. (USSR) 8, $549^{-}$(1960).

Be60. T. S. Belanova, Soviet J. At. Energy 8,462 (1961).

Be62. I. Bergquist, "Fast Neutron Radiative Capture Cross Section: in Ag, Ta, $W, A u, H g$, and U," Arkiv. Fysik 23, 425 (1962).

Be65. T. S. Belenova, A. A. Vankov, F. F. Mikhailus, and Yu. Ya. Stavisski1, "Absolute Measurement of the Absorption Crose Sectlons of Neutrons of $24 \mathrm{keV}$ EnerBy," Soviet $J$. At. Energy 19, 858 (1965); or J. Kuel. Enerey 20, 411 (1966).

Be68. I. Bergqvist, B. Lundberg, I. Milsson, and N. Starfelt, "Radiative Capture in Hickel and Bismuth of Ner.trons in the MeV Region," Nucl. Phys. Al20, 161 (1968).

Be70. I. Bergqvist, B. Lundberg, and L. Hilsson "Crose Sections for Hich-Eneres $\gamma$-Transitions from WeV lleutron Capture in ${ }^{206} \mathrm{~Pb}$," Nucl. Phys. A153, 553 (1970).

Be71. I. Bergqvist, D. Drake, and $D . K$. MCDaniels, "Spectrua of the Reaction $20 \mathrm{Q}_{\mathrm{pb}}(n, \gamma)^{209 \mathrm{pb}}$ and Semidirect Capture Theory," Phys. Rev. Letters 27, 269 (1971).

Be72a. I. Bergqvist, D. M. Drake, and D. K. MDaniels, "Rediative Capture of Fast Neutrons by " ${ }^{\circ} \mathrm{Ca}$," to be publ'shed.

Be72b. I. Bergqvist, D. M. Drake, and D. K. MCDaniels, "Rediative Capture of Energetic lieutrons by $208 \mathrm{~Pb}, "$ ilucl. Phys. Al91, 641 (1972).

Bos8. R. Booth, H. P. Ball, and M. H. MacGregor, "Neutron Activation Cross Sections at $25 \mathrm{keV}$, Phys. Rev. 112, 226 (1958); includes BesL corrections (p.c. 1971).

Br64. G. E. Brom, "Direct and Semi-Direct $(p, \gamma)$ and $(n, \gamma)$ Reactions," Nucl. Phys. 57, 339 (1964).

Ch66. A. K. Cheubey and M. L. Sehgel, Phys. Rev. 152, 1055 (1966).

C165. C. F. Clement, A. H. Lane, and J. R. Rook, "Radiative Capture by Excitation of Collecrive Vibrations," Nucl. Phys. 66, c73 (1965) and 293 (1965).

Dab4. F. J. Daly and P. F. D. Shaw, "Radiative Proton Cepture Cross Sections in Heavy Nuclei," Nucl. Pinys. 56, 322 (1964).

Da68. P. J. Daly, B. M. Seppelt, and P. F. D. Shaw, "Radiative iapture Cross Sections in Mediur-Weight and Heavy Nuclei," Nucl. Phys. A 119, 673 (1968).

De72a. J. J. Devaney and D. G. Foster, Jr., "An Eveluation of the Total Cross Section for Tungsten," Ios Alamos Scientific Laboratory report LA.-492.8 (June 1972).

De723. J. J. Devaney, "Miltiple-Reaction Correction to the Capture Cross Section," Phys, Rev. Lett. 29, 2567 (1972).

De73. J. J. Deveney, "Multiple-Reaction Correction to Reaction Cross Sections," to be published in Nuclear Science \& Engineering.

Di60. B. C. Diven, J. Terrell, and A. Hemendinger, "Radiative Capture Cross Sections for Fest Neutrons," Phys. Rev. 120, 556 (1960).

Di70. M. Diksic, P. Strohal, and G. Pet6, "Additional Measurenents of the Radiative Capture Cross Sections for 3/ NeV Neutrons," Acta Phys. Hung. 28, 257 ( 1970 ).

Dr70. M. K. Drake, "Data Formats and Procedures for the ENDF Neutron Cross Section Library," Brookhaven Nationel Leboratory Report BNL50274, Vol. 1, (1970).

Dri1. D. Drake, I. Bergqvist, and D. K. McDar.iels, "Dependence of $14 \mathrm{MeV}$ hadiative Neutron Cepture on Mass Number," Phys. Lett. 36B 557 (1971).

Dr72. D. M. Drake, S. L. Whetstone, and j. Halpern, "The Radiative Cepture of Fast Protons by Nedium Mass Nuclei," Nuclear Physics, to be published. 
Fr70. M. P. Fricke, W. M. Lopez, S. J. Friesenhahn, A. D. Carlson, and D. G. Costello, "Measurements of Cross Sections for the Radiative Capture of I-keV to I MeV Heutrons by Mo, Rin, $\mathrm{Ge}, \mathrm{Ta}, W, \mathrm{Re}, \mathrm{Au}$, and $23 \mathrm{BU}, "$ and Intern. Conf. Nuclear Deta for Reactors (Helsiniri, 1970), Vol. II, p 265.

Gi61. J. H. Gibbons, R. I. Macklin, P. D. Minler, and J. H. Neiler, "Average Radiative Cepture Cross Sections for 7 to $170 \mathrm{keV}$ Neutrons," Phys, Rev. 122, 182 (1961). See also Me63.

Gi66. J. H. Gibbons, Conf. Neut: or Cross Sections and Technology, Conf-660303, p 404 (Weshington, 1966).

Gol66. M. D. Goldberg et al., "Neutron Cross Sections," Brookhaven National Ieboratory report Ell-325, and Ed., Suppl. \& (1966).

Gov66. N. B. Gove, Nucl. Date Bl-2-1 (1966).

Gu66. H. Gutfreund and G. Rakavy, "The Direct Capture Mechanism for Intermediate Energy Nucleons," Nucl. Phys. 79, 257 (1966).

Hu71. R. Hunter, I. Stewert, and T. A. Pitterle, private commication, R. Hunter, 1971.

Jo59. A. E. Johnsrud, M. G. Silbert, and H. H. Barscha]l, "Energy Dependence of FastNeutron Activation Cross Sections," Prys. Rev. 116, 927 (1959). Renormalized to $\sigma_{F} 235$, Hu71.

Ka63. S. V. Kepchigashev, Yu. P. Popov, and F. I. Shapiro, "Capture Cross Sections in Construction Materials for Neutrons," Soviet J. At. Energy 15, 808 (1963).

Ko58. V. K. Kononov, Yu. Ya. Stavisskii, and V. A. Tolstikov, "Measurement of the Radiative Capture Cross Section of $25 \mathrm{keV}$ Neutrons," Soviet J. At. Energy 5, 1483 (1958) or J. Nucl. Energy 11, $46(1959 / 60)$.

Ko66. V. N. Kononov, Yu. Ya. Stavisskii, V. E. Kolesov, A. G. Dovbenko, V. S. Nosterenko, and V. I. Moroka, "Radiative Capture Crosa Sections for 30-170 keV Neutrons," Soviet Nucl. Phys. 4, 204 (1967), and Nuclear Data for Reactors, Vol. I, 469 (IAEA, Paris Conf, 1966); also A. G. Dovbenko et al., Conf. Study of Nuclear Structure with Neutrons, Paper 199 (Antwerp, 1965).

La59. A. M. Lane and J. E. Lynn, "Analysis of Experimental Data on Nucleon Cayture Reections," Nucl. Phys. 12, 646 (1959).

Je58. A. I. Leipunski et a.., "Measurements of Radiative Capture Crose Sections for Fast Neutrons," Geneva Conf. Peaceful Uses At. Energy, A/conf 15, 50 (1958), P/2219. Renormalized, stbl.

Li67. D. Lister, A. B. Smith, and C. Dunford Phys. Rev. 162, 1077 (1967).

Lo68. G. Longo and F. Saporetti, "Interference between Collective and Direct liucleon Radiam tive Capture," Nuovo Cimento 56B, 264 (1968).

L069. G. Longo and F. Saporetti, "Radiative Capture for Intermediate-Enerey Neutrons," Nucl. Phys. Al27, 503 (1969).
Iro70. G. Longo and F. Seporetti, "Different Contribut,ions of Direct and Collective Capture in $(p, \gamma)$ and $(n, \gamma)$ Reections," Nuovo Cimento 67A, 356 (1970).

Ly59. H. S. Lyon and R. L. Mecklir, Phys. Tiev. 134, 1619 (1959). Renormalized, Gol6́.

Maj7. R. L. Macklin, N. H. Lazar, anl W. S. Lyon, "Teutron Activaticn Cross Sections with Sb-Be Meutrons," Phys. Rev. I07, 504 (1957).

Me63. R. L. Macklin, J. H. Gibbons, and T. Inada, "Neutron Capture Cross Sections Near $30 \mathrm{keV}$ " tiucl. Phys. 43, 353 (1963).

Me66. M. J. Mertin, Mucl. Date Bl-1-63 (1966).

Ma67. R. I. Macikin and J. H. Gibbons, "CaptureCross-Sections Studies for 30-220-keV Neutrons Using a heu Techniaue," Phys. Rev. 159, 1007 (1967).

Me73. D. K. MeDeniels, private communicaticn, 1972.

Mi62. J. A. Miskel, K. V. Marsh, M. Lindner, and R. J. Hagie, "Neutron Activation Cross Sections," Phys. Rev. 128, 2717 (1962). Renortalized $\sigma_{F} 235 \mathrm{U}$, Fu71.

Na71. R. J. Nagle, J. H. Landrum, and $M$. Lindner, "Neutron Capture Cross Sections in the MeV Range," 3rd. Conf. Deptron Cross sections and Technology, Conf-710301, Vol. I. p 259 (Dak Ridge, 1971).

Ni58. A. O. Nier reconendation in $\mathrm{K}$. Way et al. Muclear Deta Sheets, Appendix 2, National Research Council (1958).

P858. M. V. Pasechnik et al., "Fast Neutron Scattering and Capture by Atomic Nuclei," Geneva Conf. Peaceful Uses At. Energy, $\mathrm{A} / \mathrm{Con} 15,18$ (1958), $\mathrm{P} / 2030$; also $\mathrm{Yu} . \mathrm{V}$. Gofman and M. V. Pasechnik, USSR Conf. Low Energy Iuclear Reactions, D 15 (1957). Renormelszed, Gol66.

Pe58. J. L. Perkin, I. P. O'Conner, and R. F. Coleman, "Radiative Capture Cross Sections for $14.5 \mathrm{MeV}$ Neutrons," Proc. Phys. Soc. (Lond.) 72, 505 (1958).

P067. W. P. Ponitz, D. Kompe, K. H. Beckerts, and H. O. Menlove, in the sequence of papers: D. Kompe, "Capture Cross Section Measurements," Hucl. Phys. Al33, 513 (1969), H. 0 . Menlove and W. P. Poñtz, Nucl. Sci. Eng. 33,24 (1968), and the Karlsruhe reports KFK-454, KFK-455, KFK-635.

Sc72. F. A. Schmittroth, Trans. Am. Nucl. Soc. 15, 464 (1972) and "Theoretical Caleulations of Fast Neutron Capture Cross Sections," Hanford Engineering Laboratory report HEDLTME-71-106, (1971).

Sp69. D. Sperber, "Statistical Theory of $(n, \gamma)$ and $(p, r)$ Excitation Functions," Phys. Rev. 184, 1201 (1969).

St60. Yu. Ya. Stavisskii and V. A. Tolstikov, "Cross Sections for the Radiative Capture of Fast Neutrons by the isotopes v51, Nb93, w186, and T1205," Soviet J. At. Energy 9, 942 (1961), or J. Nucl. Energy 16, 496 (1962) Renormalized to $\sigma_{F} 235 \mathrm{U}, \mathrm{Hu} 71$.

St6l. Yu. Ya. Stavisskii anj A. B. Shaper, 
"Past-lieutron Radiative Cepture Cross Sections in Tungsten and Nolyibdemum," Sov. Prog. Neut. Phys., p 227 (196I); 27so ANI-TRANE-168.

Ve67. E. V. Verdieck and J. M. Miller, "Radiative Capture and Neutron Bmission in $\mathrm{La} 139+\mathrm{Cr}$ and Cel42, " Phys. Fer. 153, 1253 (1967).

Wa66. X. Way, Nucl, Data Bl-1-1 (1966).
Yo72. P. G. Young, privete commicstion (1972). He are grateful for this timely assistance by Dr. Young.

2a68. G. G. Zaikin, "Cross Sections for Redfative Capture of Fast Reutrons by $\mathrm{Cu}^{63}, \mathrm{Cu}^{65}$, and 1186," Soviet J. At. Bnergy 25, 1362 (1968). Renormalized o $\sigma_{F} 35 \mathrm{~V}$, HuT1.

\section{AFPRTDIX}

ETDF/3-FORMAI. INISTMG OF TUWGSTRY CROSS SBCTIORS

The cspture cross section of tungst:a and its isotopes from abont $0.005 \mathrm{HeV}$ to $20 \mathrm{HeV}$ are listed in BDF/B format. Holierth deserlptive loforzation is onitted here because it is included in the text.

TUNGSTEN SMOUTH RADTATIVE CAPIUNE CHUSS SECIIUN MATERIAL 740 $7.40000+04$ 1.M?21 $7+0$ ?

$0.00000+0.0 .4051+00$

\begin{tabular}{|c|c|c|c|c|c|c|}
\hline & 17 & & 2 & & 23 & \\
\hline $\begin{array}{l}5.8 \\
1.1\end{array}$ & $\begin{array}{l}+03 \\
+04\end{array}$ & ל6. & $\begin{array}{l}-01 \\
-01\end{array}$ & 7.5 & $\begin{array}{l}+03 \\
+04\end{array}$ & $\begin{array}{l}5.78 \\
3.74\end{array}$ \\
\hline & +04 & 3.17 & -01 & 2.5 & +04 & 2.5 \\
\hline & +04 & ל.4. & -01 & 4. & $+v 4$ & 2.28 \\
\hline & +04 & $1.9]$ & -01 & 7. & +114 & 1.07 \\
\hline & $+n 4$ & 1.71 & -01 & 1. & +05 & 1.25 \\
\hline 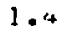 & +05 & 1.12 & -61 & 1.6 & +05 & Y. 45 \\
\hline & +05 & 0.37 & -62 & 2.4 & +05 & 7.11 \\
\hline & +05 & $n .97$ & -02 & 3.4 & +45 & 5.68 \\
\hline & $+1) 5$ & 4.211 & $-0<$ & 5.0 & -US & 4.05 \\
\hline , & +05 & 4.11 & -02 & $1 \cdot v$ & $+0 k$ & 3.42 \\
\hline 1. & +05 & לח. & -02 & 2.0 & +46 & ?. 79 \\
\hline & +06 & 1.46 & $\begin{array}{ll}-112 \\
-0.3\end{array}$ & 3.4 & +116 & 1.49 \\
\hline 7 & $\begin{array}{l}+06 \\
+06\end{array}$ & $\begin{array}{l}1.07 \\
7.7\end{array}$ & $\begin{array}{l}-03 \\
-114\end{array}$ & 6.3 & $\begin{array}{l}+00 \\
+06\end{array}$ & 9.1 \\
\hline & +06 & $1.3 \mathrm{~J}$ & -03 & 1. & +47 & .48 \\
\hline & +07 & 1.35 & -0.3 & 1.3 & +47 & 1.22 \\
\hline 1. & +07 & 4.5 & -04 & 2.0 & +07 & 2.0 \\
\hline
\end{tabular}

$\begin{array}{ll}0 & \\ & 4 \\ -01 & 4 . \\ -01 & 1.8 \\ -01 & 3.8 \\ -01 & 5 . \\ -01 & 8 . \\ -01 & 1.2 \\ -02 & 1.8 \\ -02 & 2.6 \\ -02 & 4.6 \\ -02 & 0 . \\ -02 & 1.5 \\ -02 & 2.5 \\ -02 & 3.5 \\ -04 & 6.5 \\ -04 & 8.5 \\ -01 & 1.1 \\ -03 & 1.4 \\ -04 & \end{array}$

2

.035 .21

.043 .54

$+04 \quad 2.67$

.042 .02

$+041.815$

$+051.31$

$+059.22$

.056 .67

$+055.21$

$+054.44$

$+063.36$

$+062.06$

$+062.39$

$+068.8$

.061 .00

$+071.51$

$+071.0$ $\begin{array}{lll}740 & 1451\end{array}$

$740 \quad 3102$

$53740 \quad 3102$

$740 \quad 3102$

$-017403102$

$\begin{array}{rlll}-01 & 740 & 3102\end{array}$

$-017403102$

- $01740 \quad 3102$

$-017403102$

$-017403102$

$-027403102$

$-027403102$

$-027403102$

$\begin{array}{lll}-02 & 740 & 3102\end{array}$

$-027403102$

$-027403102$

$\begin{array}{rll}-03 & 740 & 3102\end{array}$

$-047403102$

$-037403102$

$-037403102$

$-037403102$

7403102

TUNGSTEN-182 SMOOTH FADIATIVE CAPTURE CROSS SECTION

$7.41820+041.80385+02$

$0.00000 * 0 \div 6.19140+06$

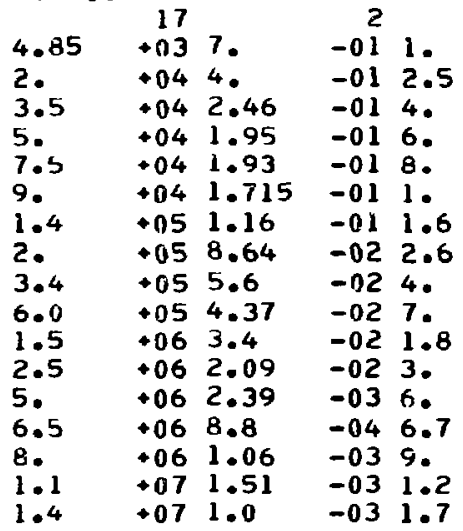

\section{0}

4

51
$+045,83$

$+043.31$

$+042.19$

$+041.915$

$+041.89$

$+051.56$

$+051.03$

$+056.87$

$+055.13$

$+054.23$

$+063.12$

$+061.49$

$+061.07$

$+06 B .7$

.061 .33

.071 .35

$+074.6$
MATERIAL $742 \quad 742 \quad 1451$

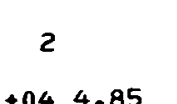

7423102

517423102 7423102

$-017423102$

$-017423102$

$-017423102$

$-017423102$

$-017423102$

$-017423102$

$-027423102$

$-027423102$

$-027423102$

$-027423102$

$-027423102$

$-027423102$

$-047423102$

$-047423102$

$-037423102$

$-037423102$

$-047423102$ 


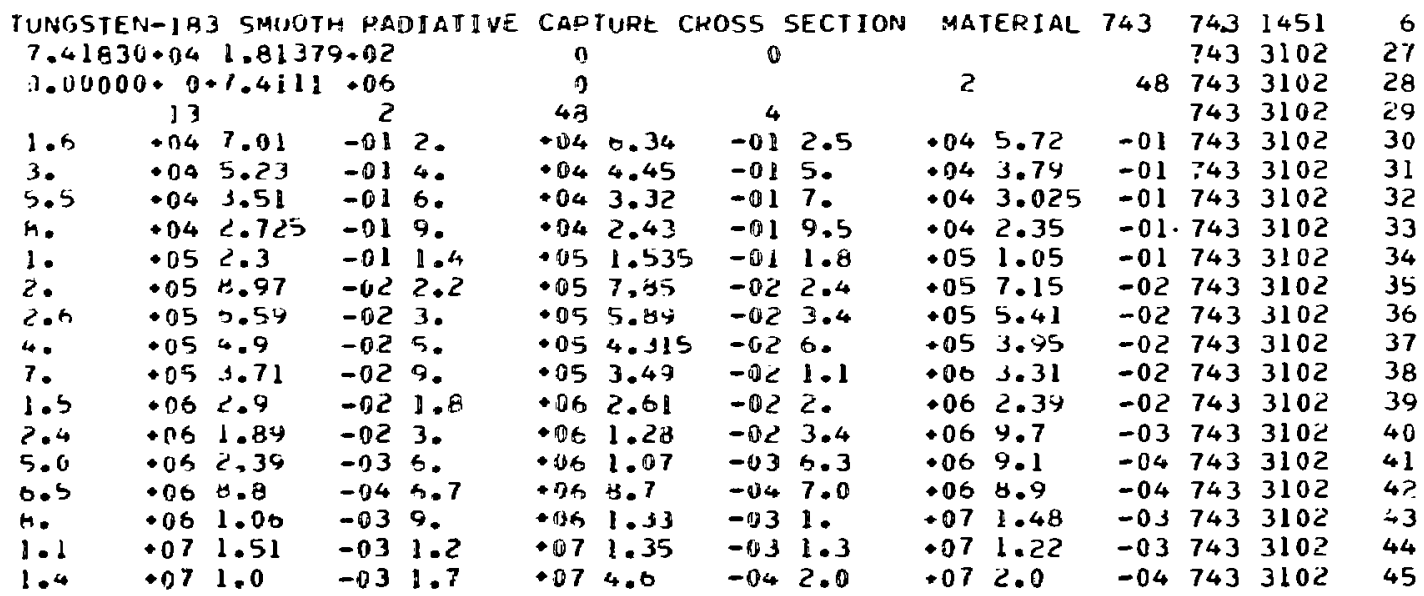

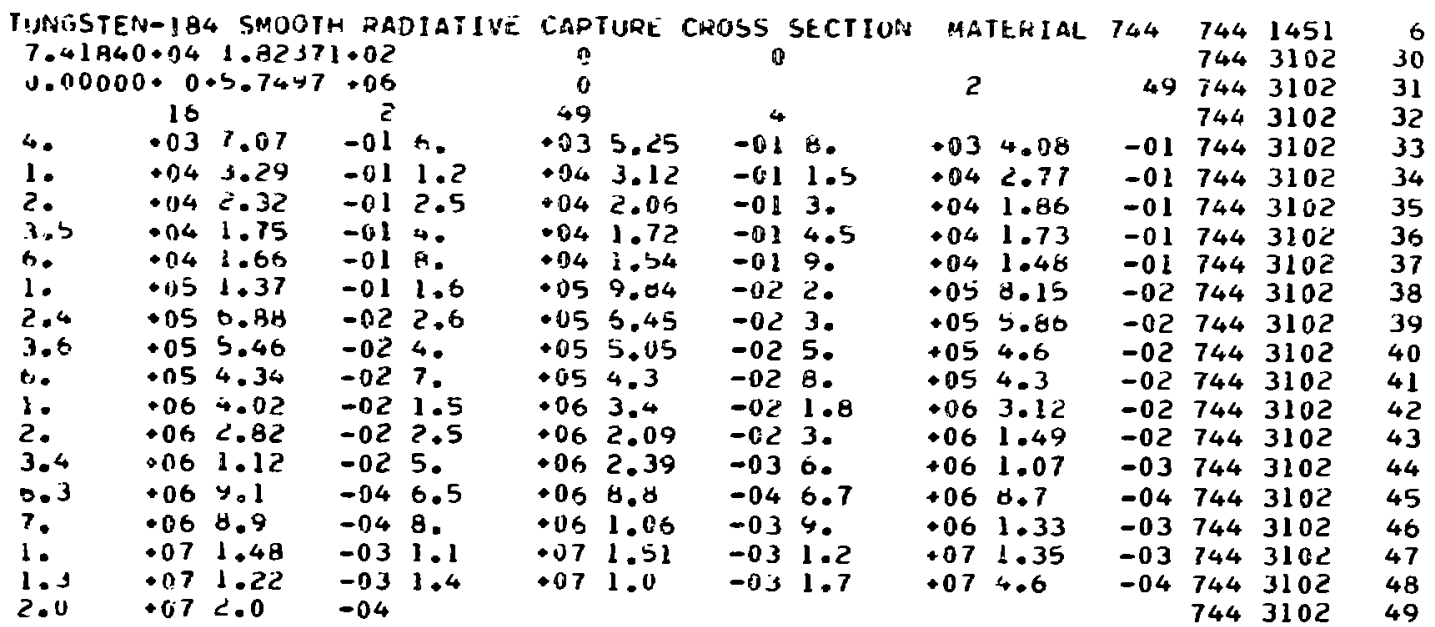

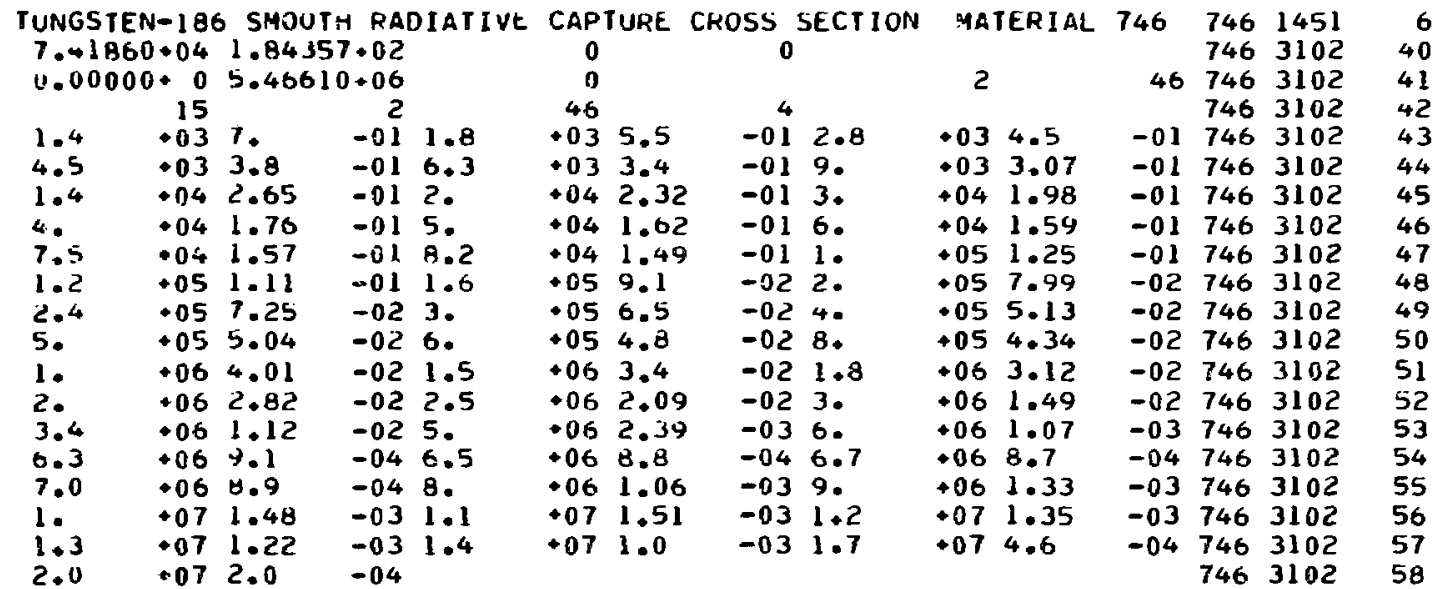




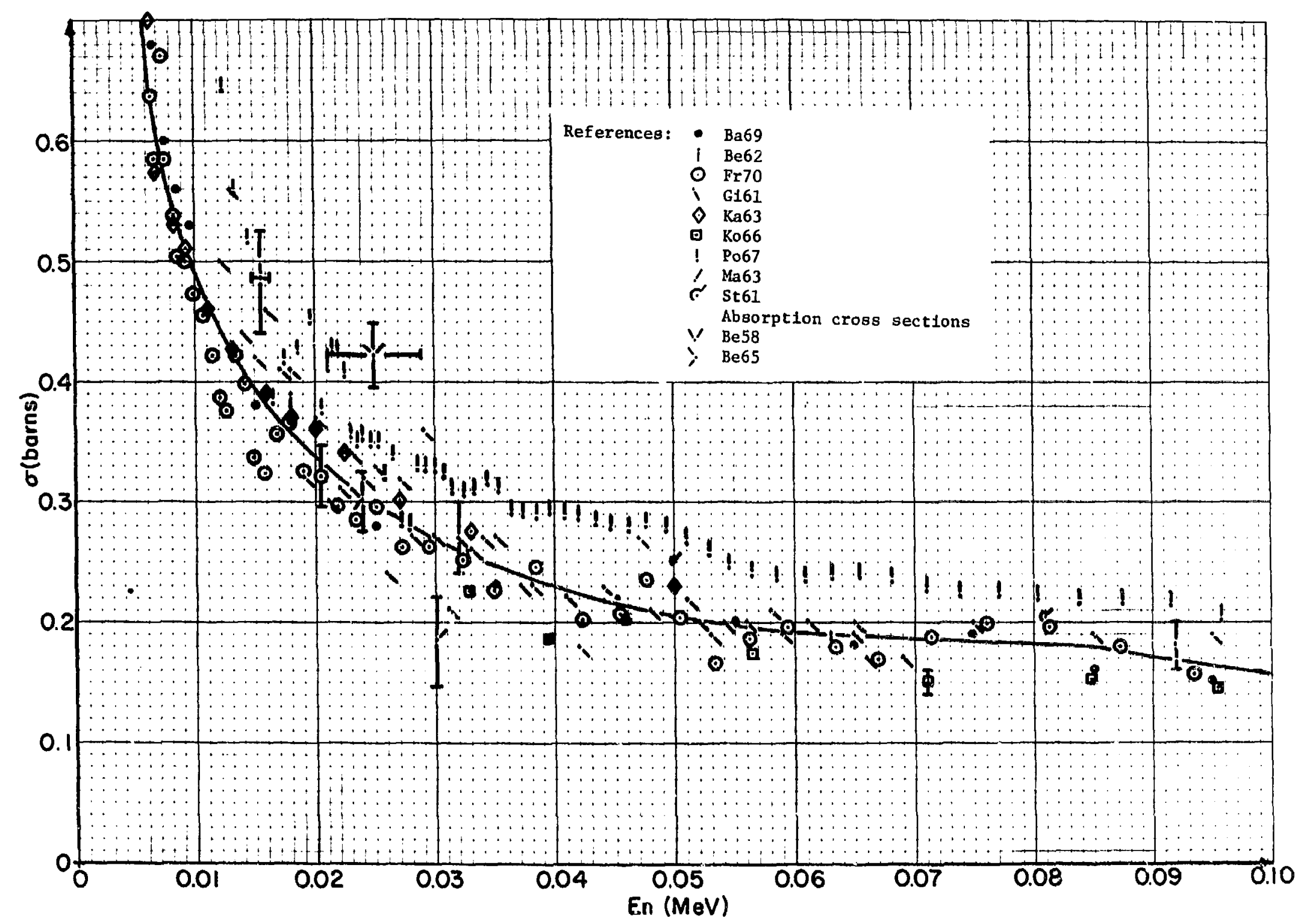

Fis. 1. Natural tungsten smooth radiative capture cross section. 
$\boldsymbol{\infty}$

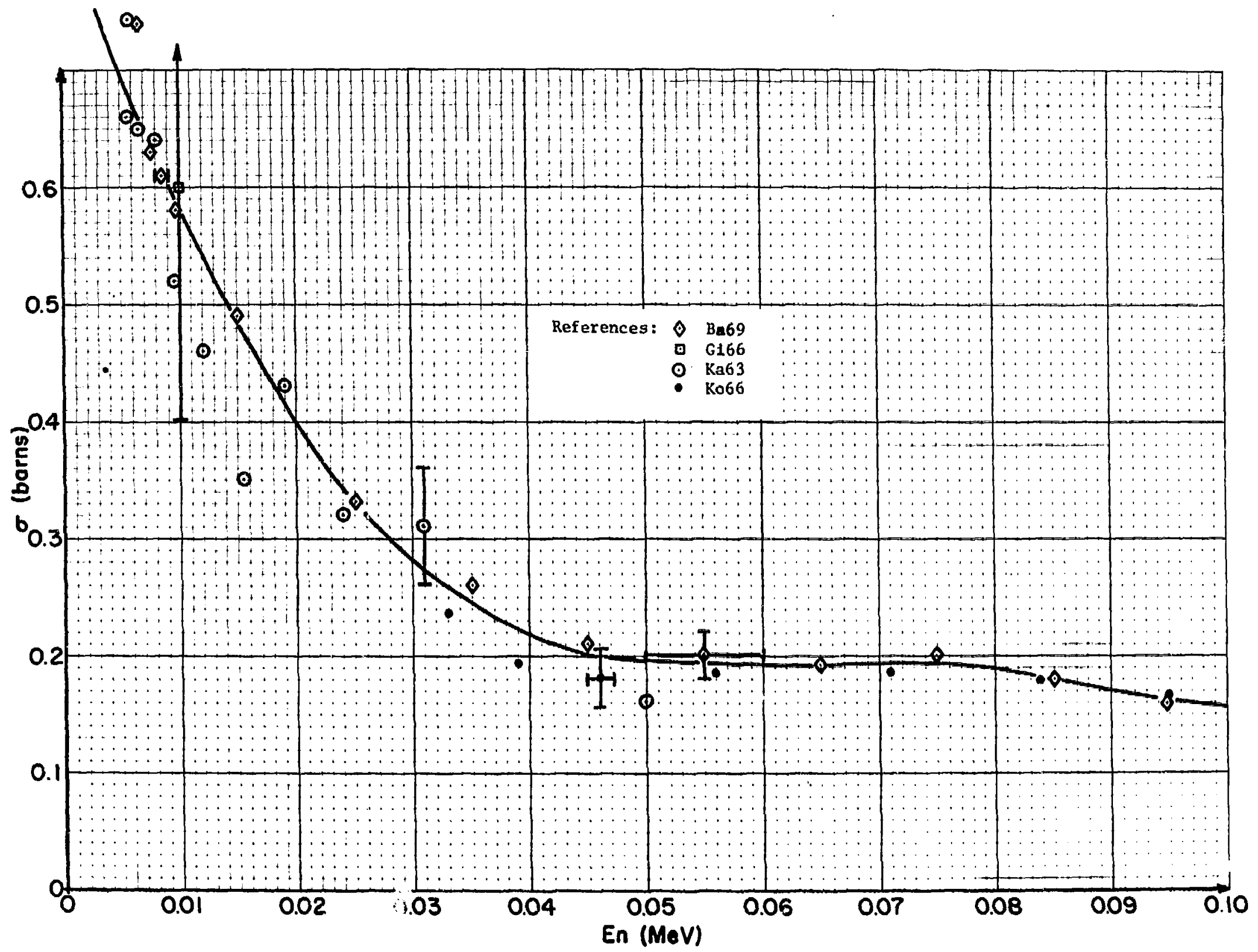

Fig. 2. Tungsten-182 smooth radiative capture cross section. 


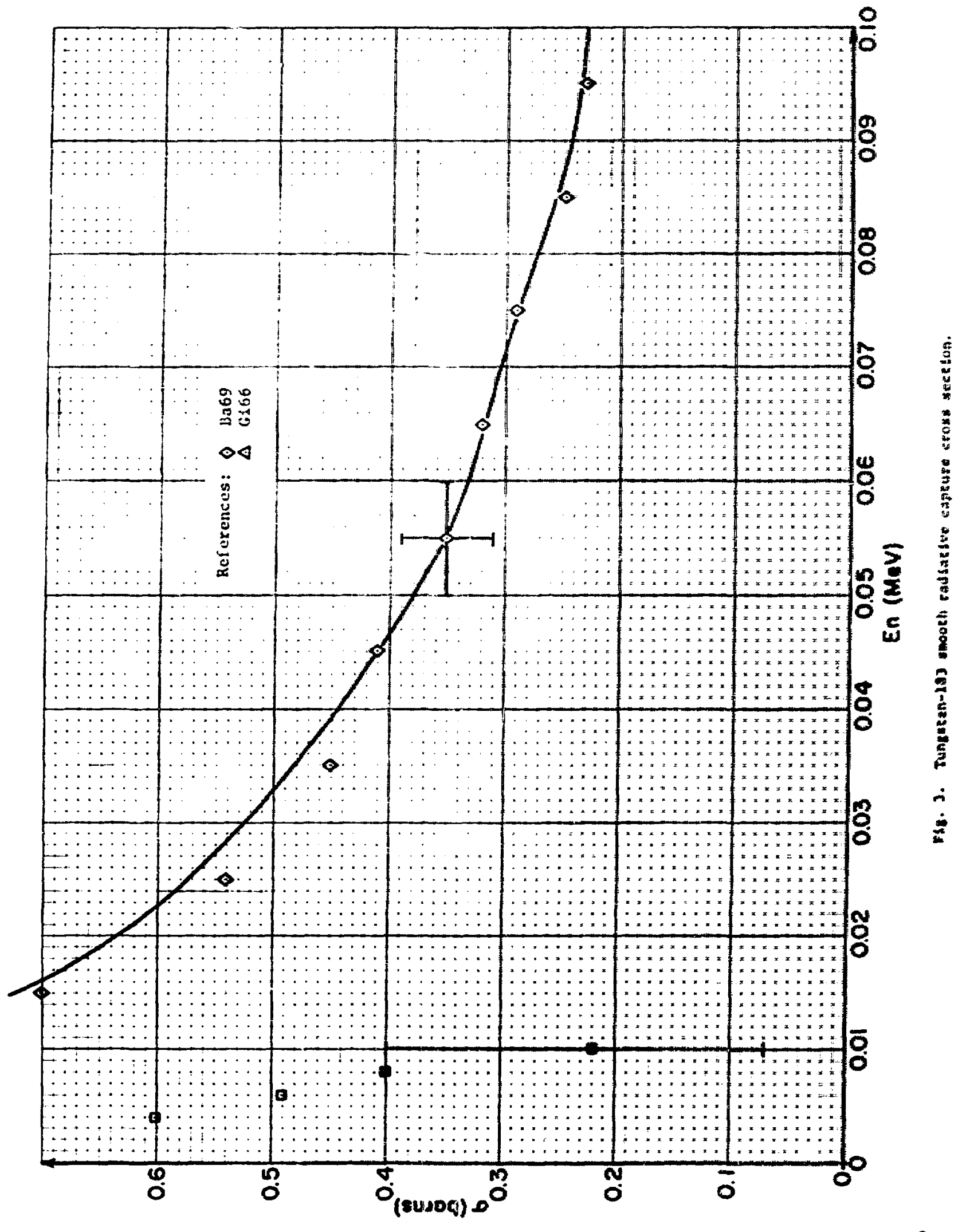




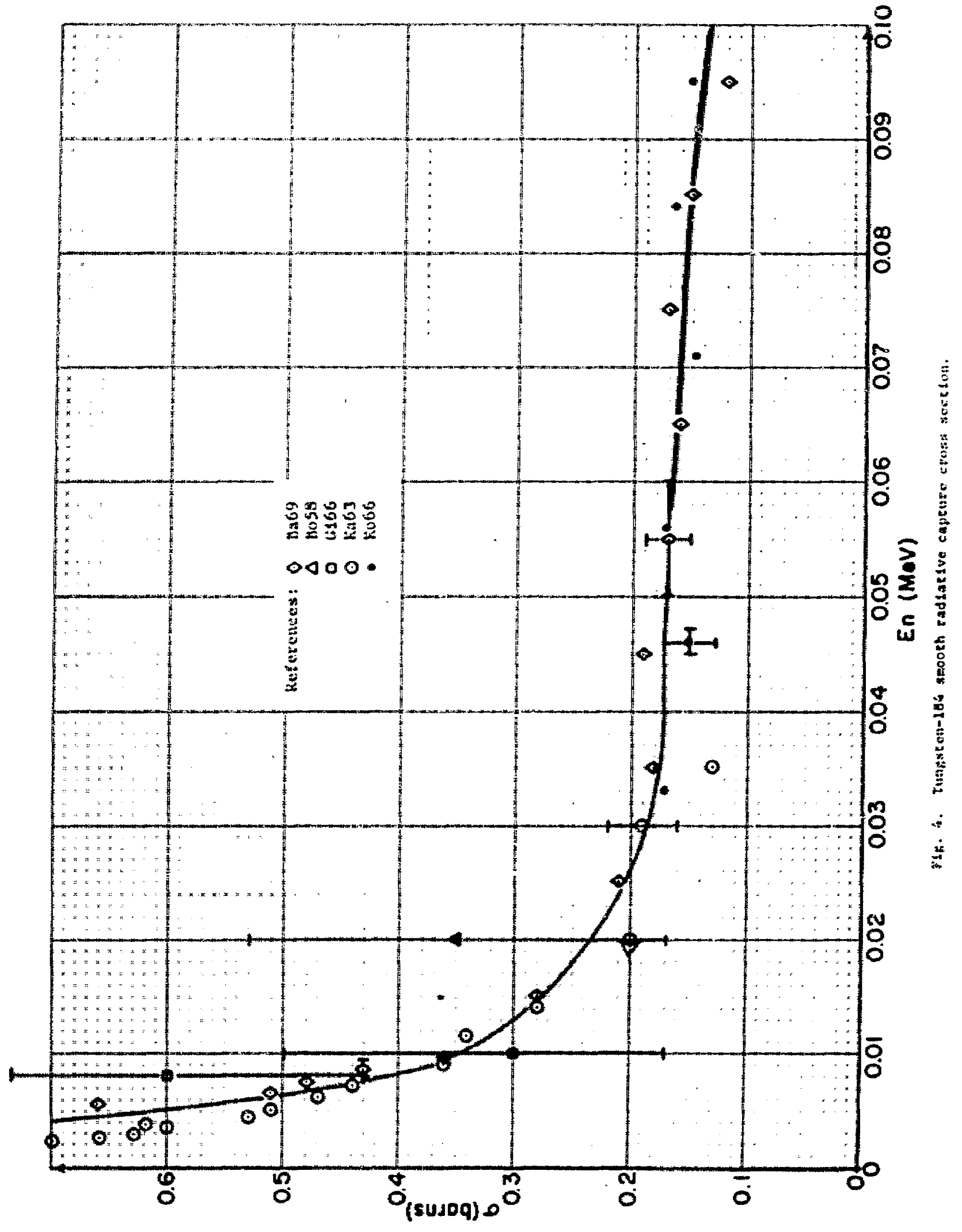




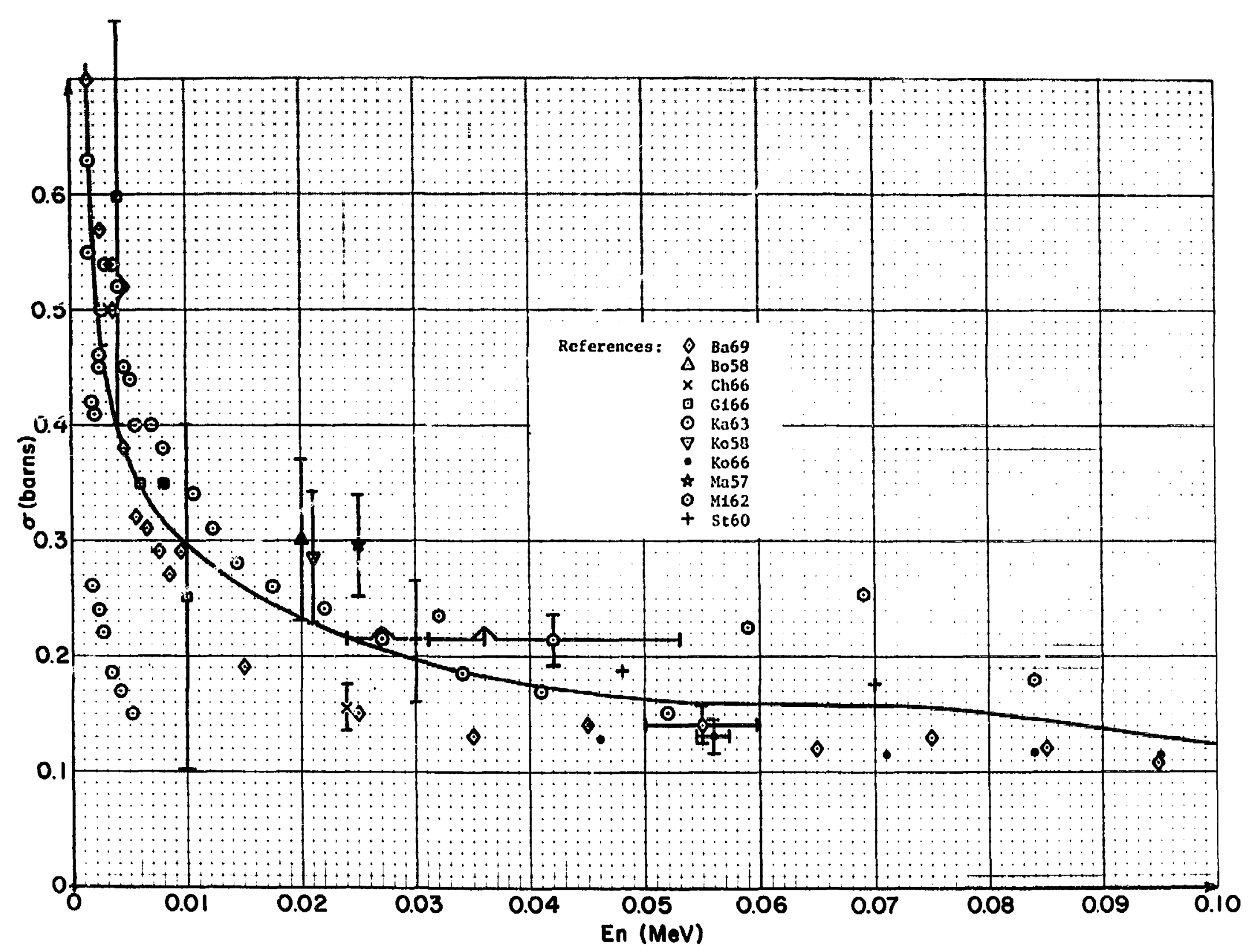

F18. 5. Tungaten-186 omooth radiative capture cross section. 


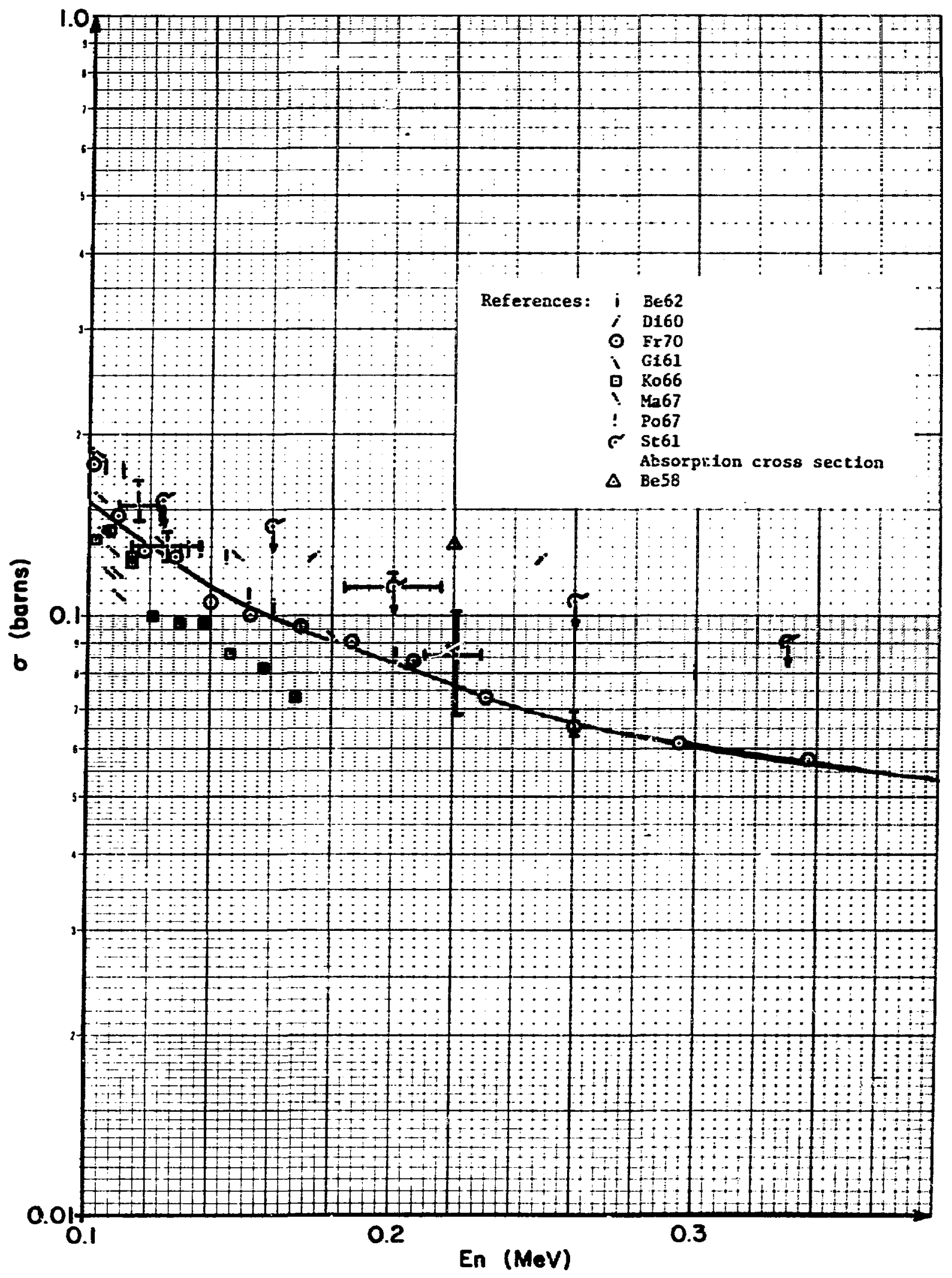

Fig. 6. Natural tungsten smooth radiative capture cross section. 


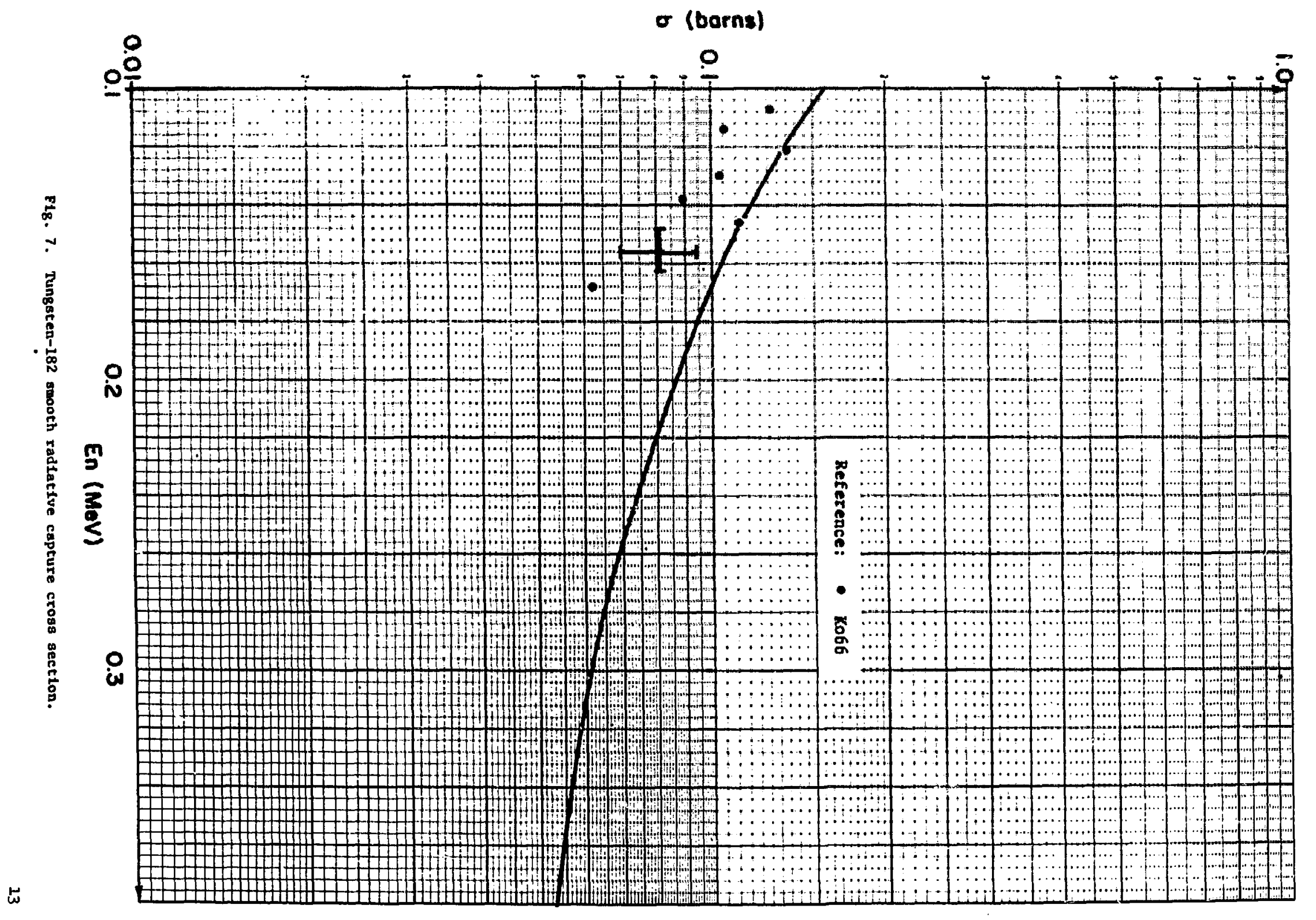




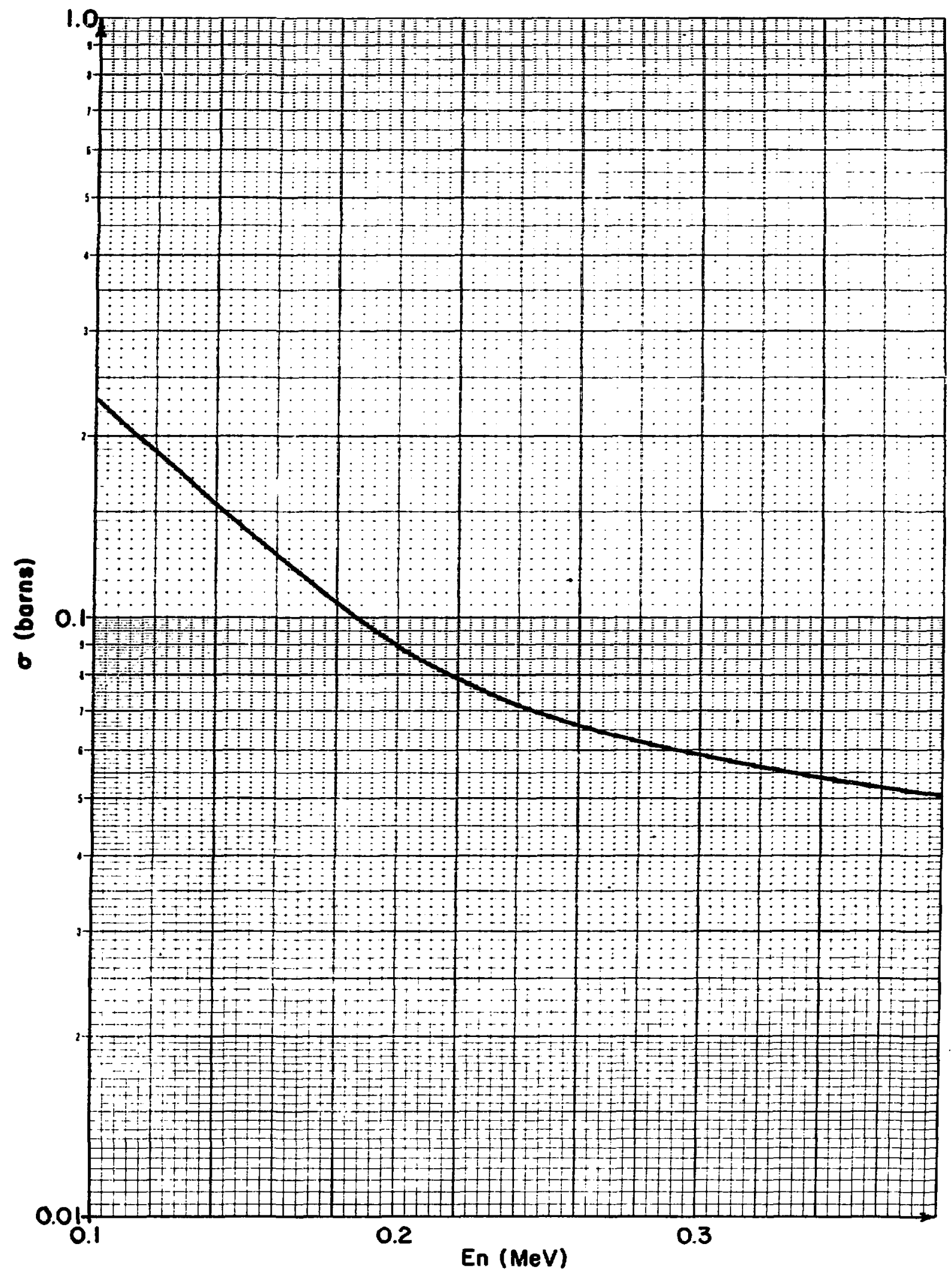

F1g. 8. Tungsten-183 smooth radlative capture cross sect1on. 


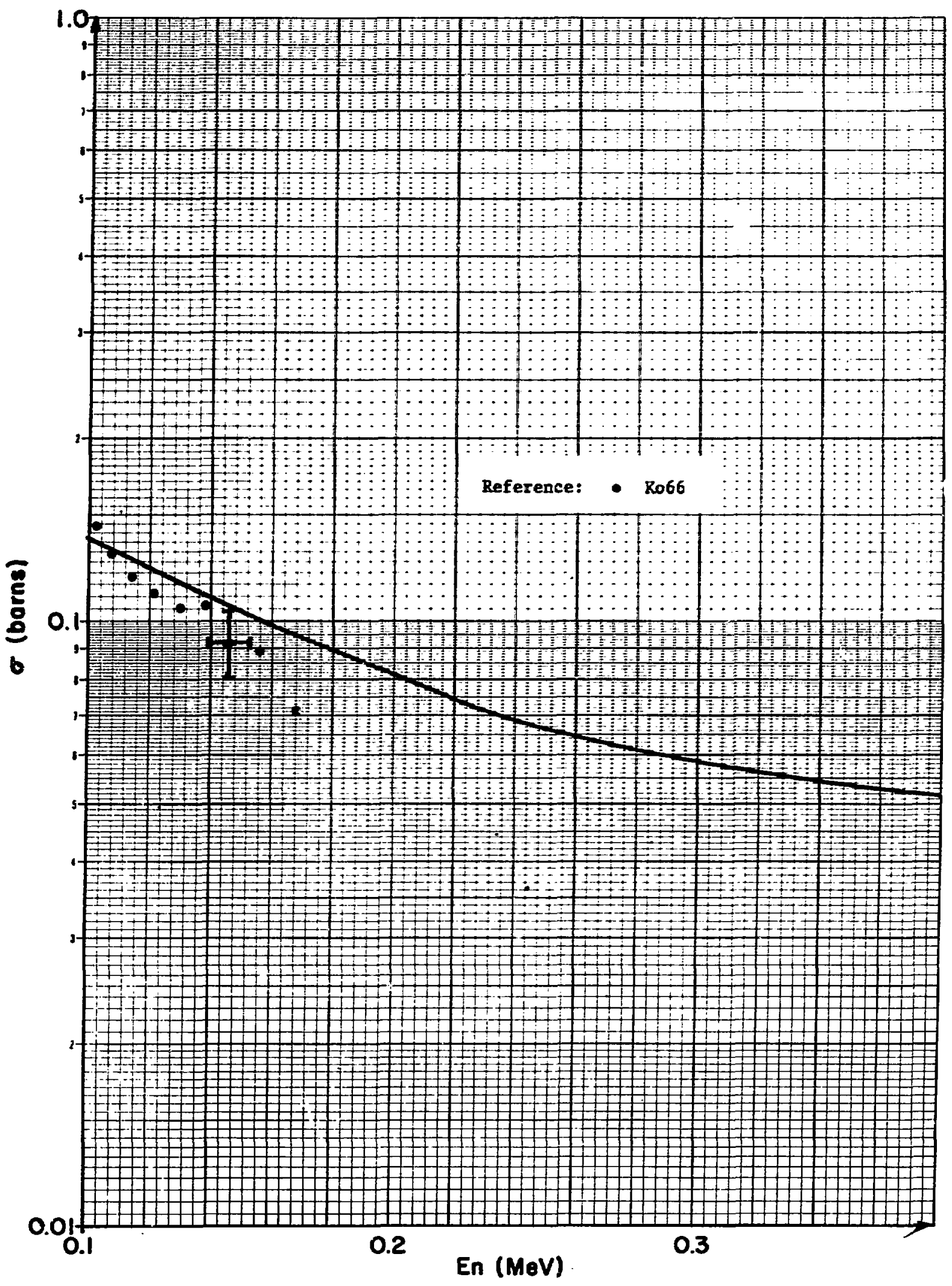

Fig. 9. Tungsten-184 smooth radiative capture cross section. 


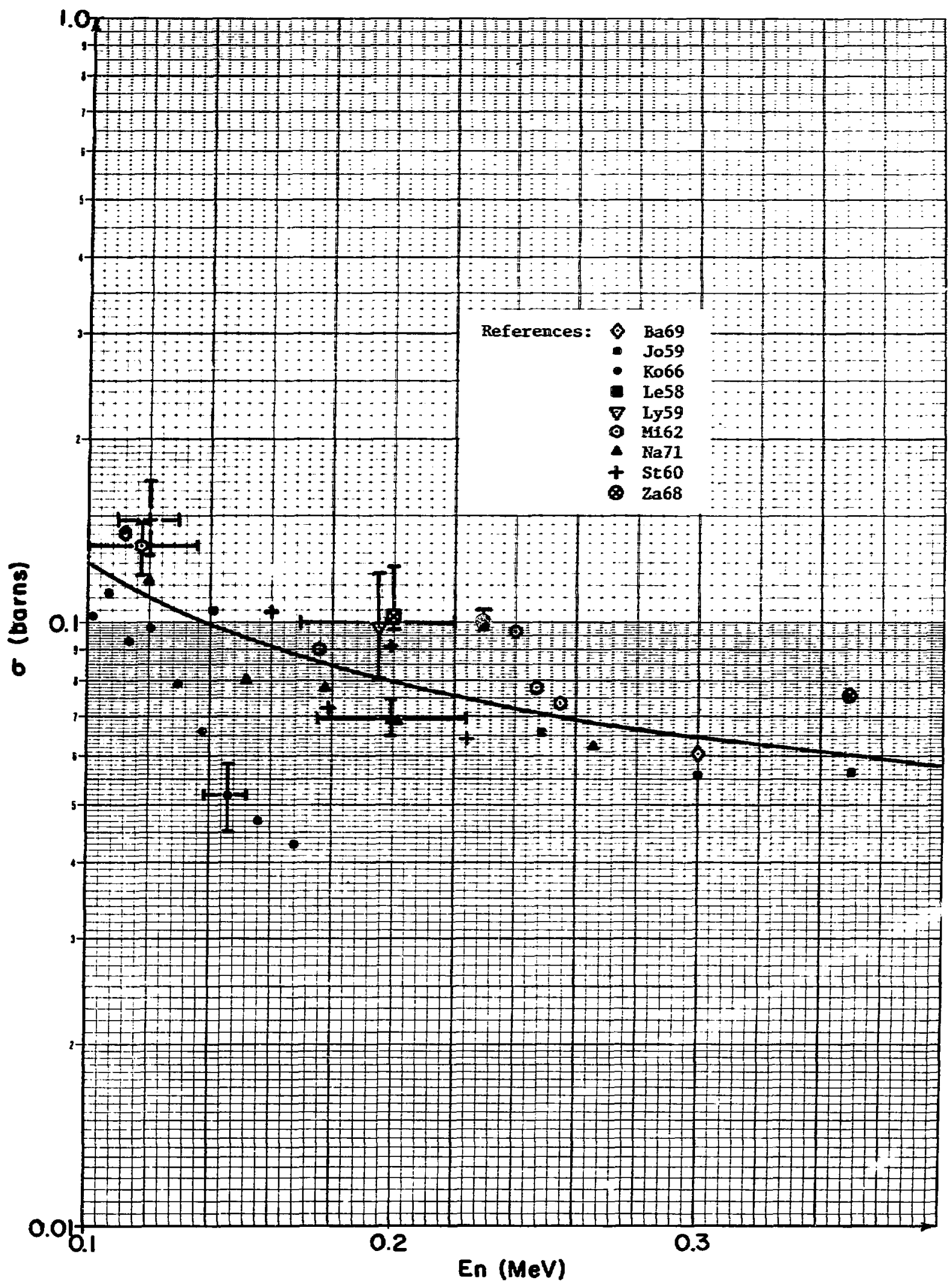

F1g. 10. Tungsten-186 smooth radlative capture cross section. 


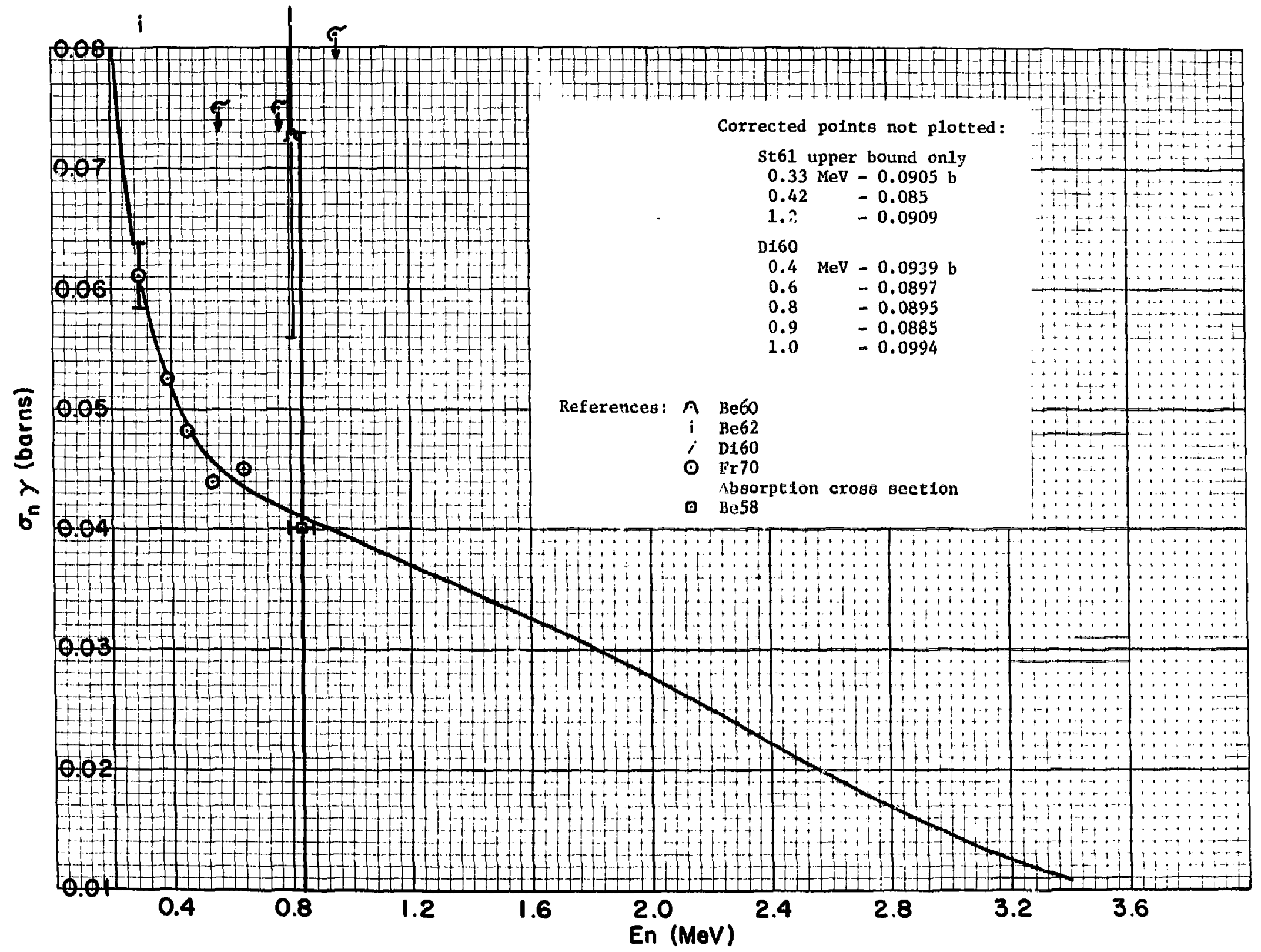




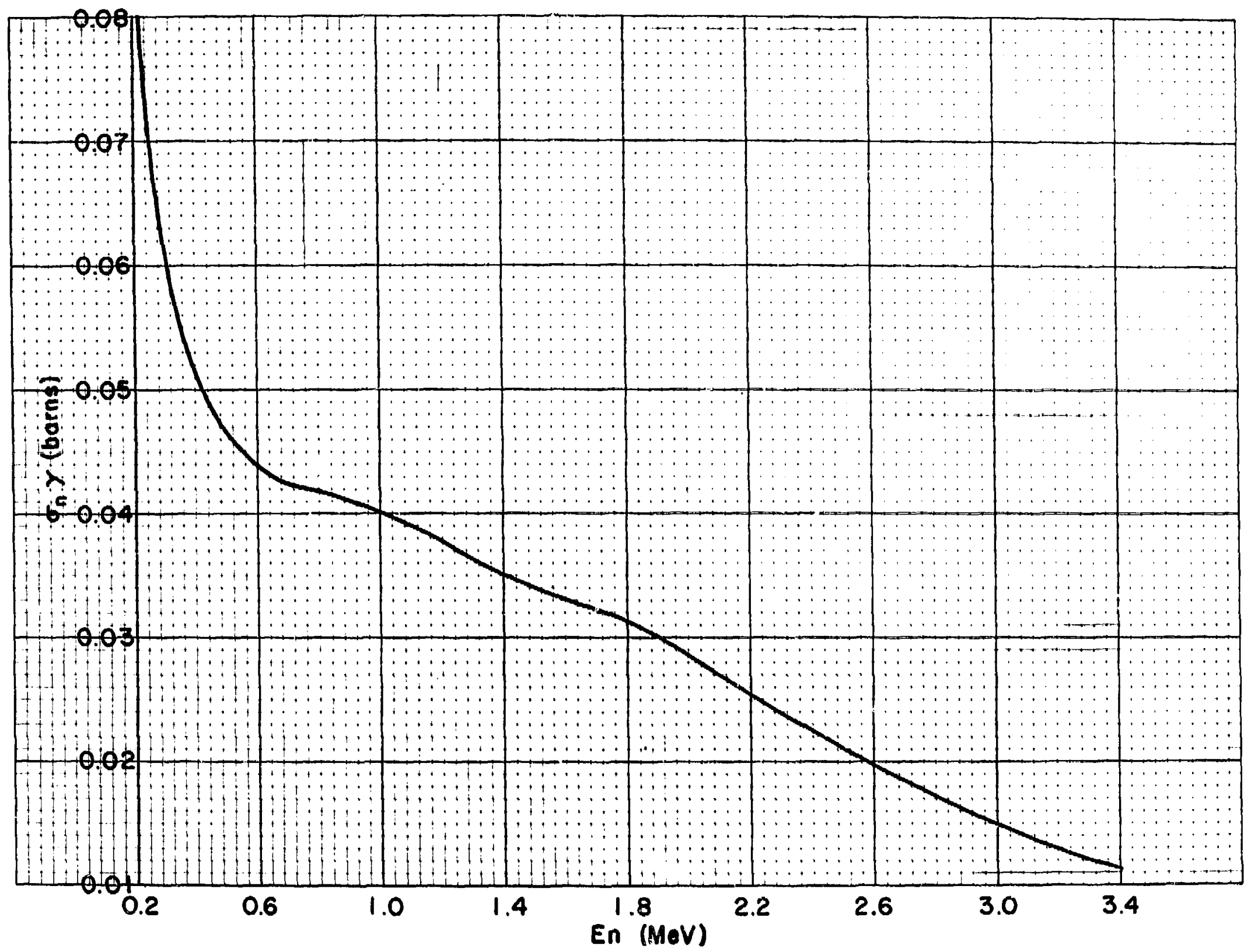

Fig. 12. Tungsten-182 radiative capture cross section. 


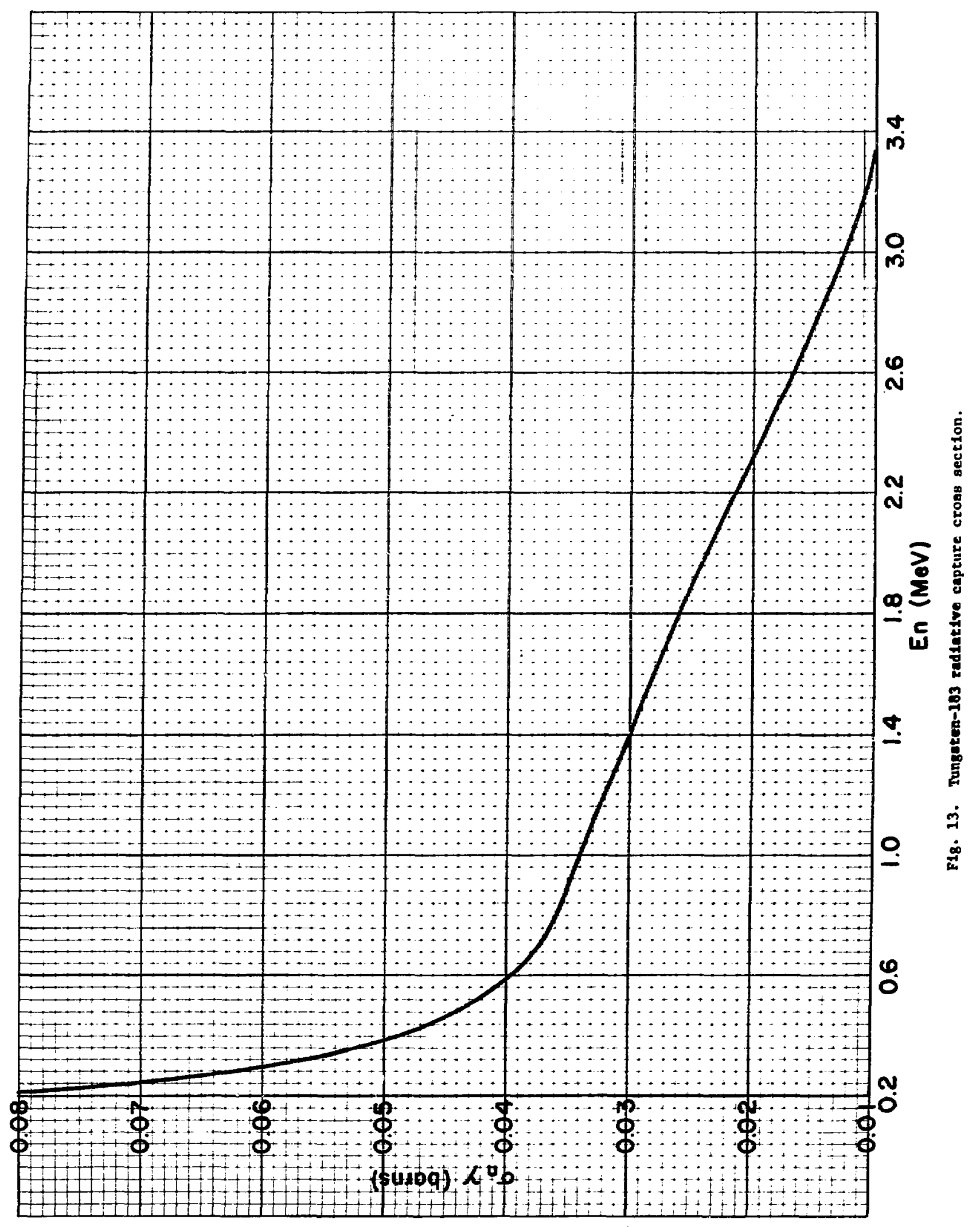




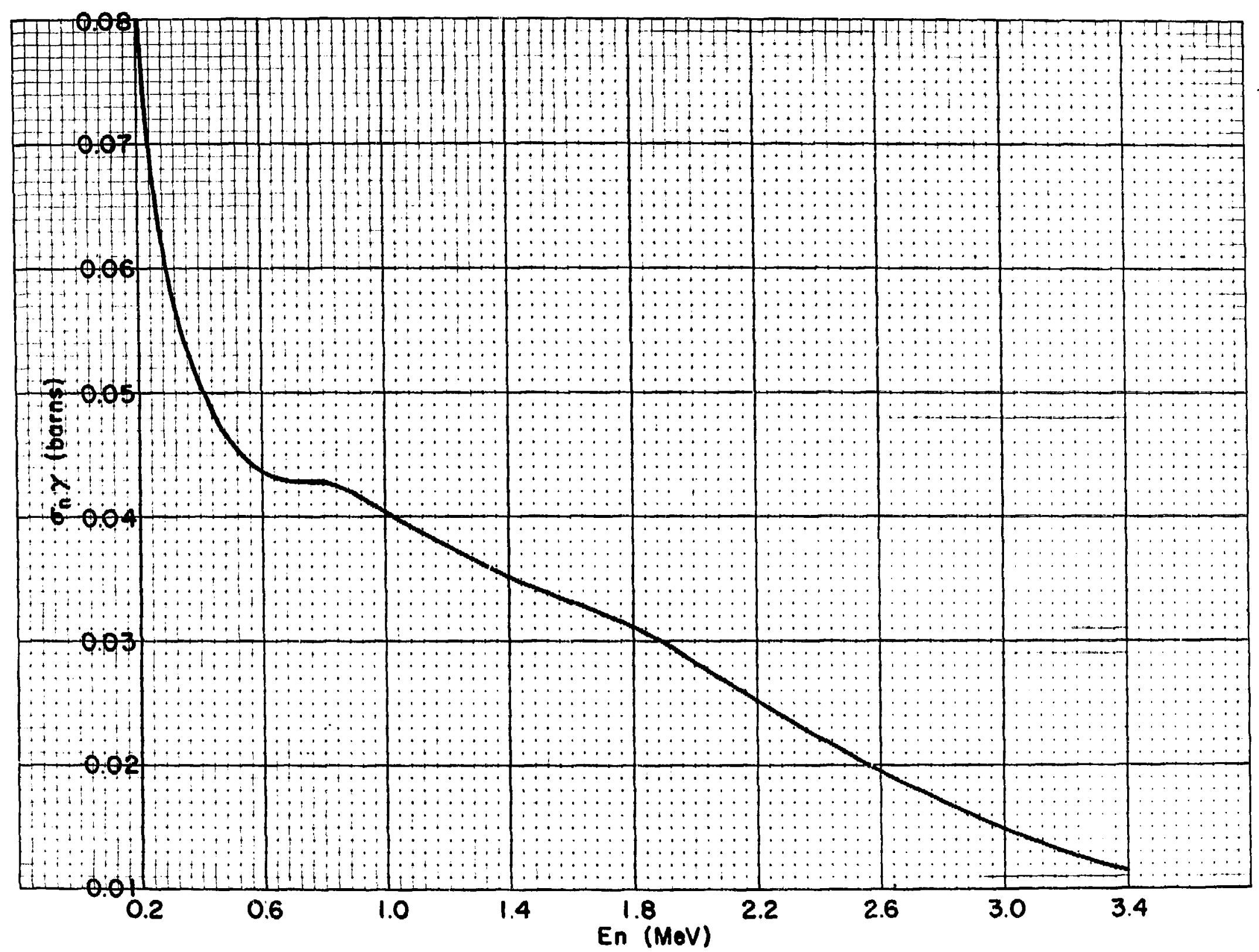

F1g. 14. Tungsten-184 radiative capture c oss section. 


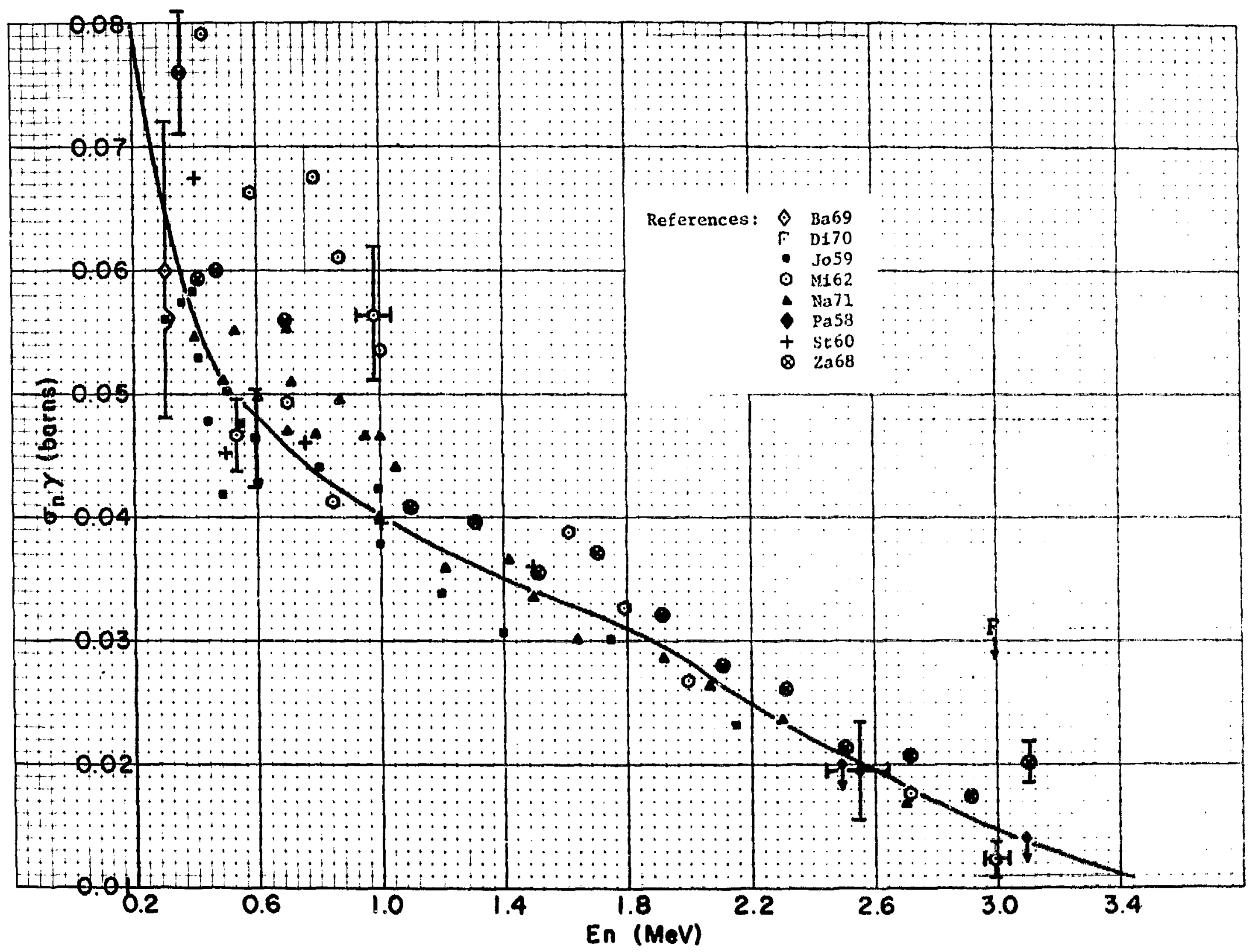

18. 15. Tungaten-186 radiative capture cross section. 


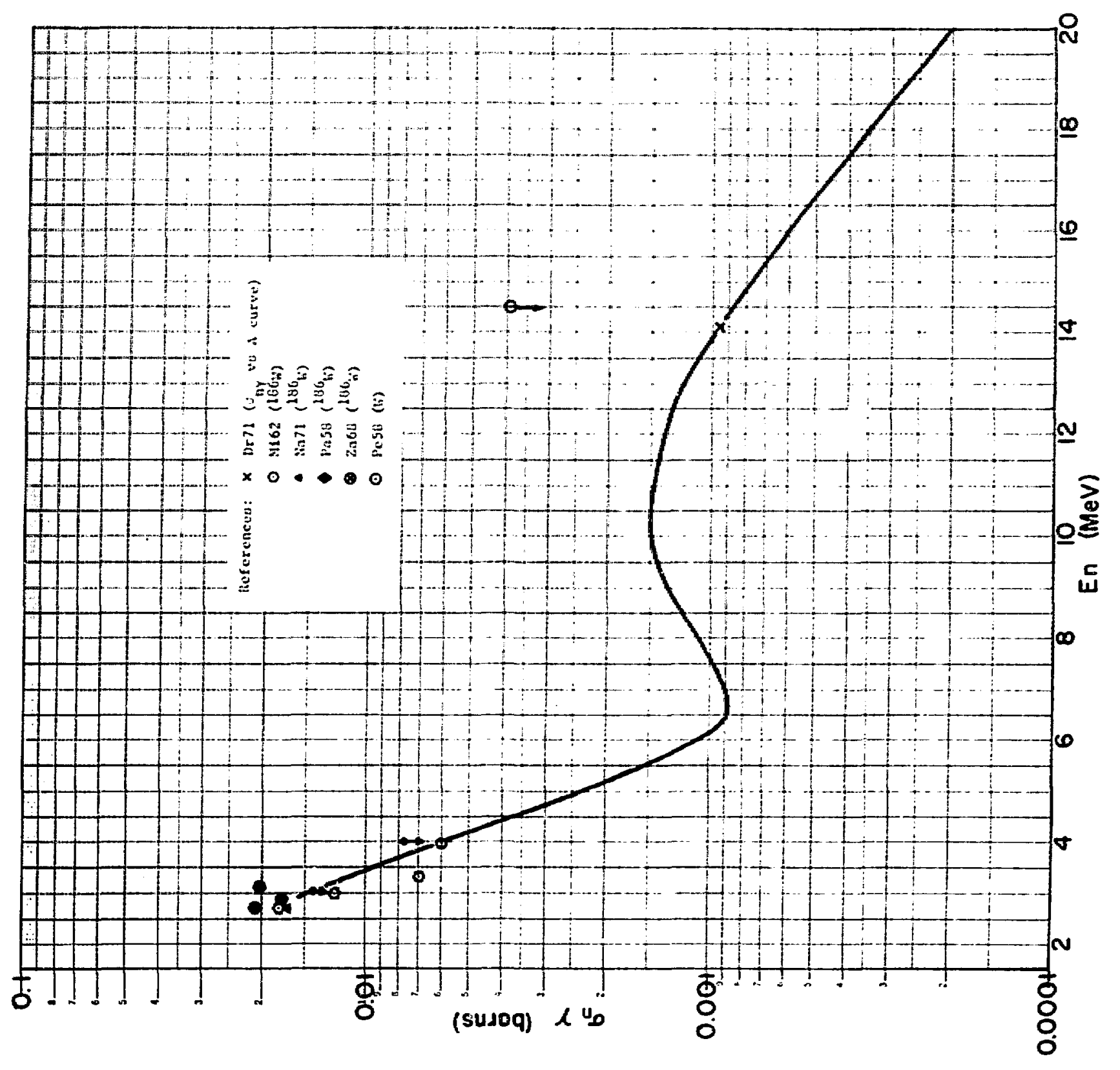

Fig. 16. Tungsten radiative capture cross section. 